\title{
Sons da alfabetização no Brasil Império: atualidade de Castilho e Jacotot ${ }^{1}$
}

Literacy sounds in Brasil Empire: actuality Castilho and Jacotot

Sounds of literacy in Brazil Empire: present of Castilho and Jacotot

\author{
Suzana Lopes de Albuquerque \\ Instituto Federal de Educação, Ciência e Tecnologia de Goiás (Brasil) \\ https://orcid.org/0000-0002-2001-5942 \\ http://lattes.cnpq.br/8411090283710343 \\ suialopes@hotmail.com \\ Carlota Boto \\ Universidade de São Paulo (Brasil) \\ https://orcid.org/0000-0002-7389-2391 \\ http://lattes.cnpq.br/2170526237232776 \\ reisboto@usp.br
}

\section{Resumo}

Ao indicar a "instrução fônica sistemática" como um de seus princípios norteadores, a Política Nacional de Alfabetização - PNA (2019) ressoa uma latente discussão metodológica imperial que perpassava as querelas entre as marchas sintética e analítica no ensino da língua materna. Esse artigo apresenta as matrizes do método fônico, criado pelo português António Feliciano de Castilho (1855), e do método analítico do Ensino Universal, criado por Joseph Jacotot (1834), que circularam e geraram embates em solo brasileiro no século XIX. Restringir as divergências do processo de alfabetização ao aspecto metodológico da adoção dessas marchas reitera o viés tecnicista desacoplado do contexto social, histórico, político e cultural dos sujeitos envolvidos.

Palavras chave: Alfabetização. Castilho. Jacotot.

\footnotetext{
${ }^{1} \mathrm{O}$ presente trabalho inscreve-se no âmbito do projeto temático da Fundação de Amparo à Pesquisa do Estado de São Paulo intitulado "Saberes e práticas em fronteiras: por uma história transnacional da educação" (Processo Fapesp: 2018/26699-4).
} 


\begin{abstract}
In order to indicate the "systematic fonic education" as one of its guiding principles, the National Literacy Policy (2019) resonates a latent imperial methodological discussion that perpetrated the quarrels between the synthetic and analytical marches in the teaching of the mother tongue.This article presents the arrays of the phonic method created by the Portuguese António Feliciano de Castilho (1855) and the analytical method of Universal Education created by Joseph Jacotot (1834), that circulated and generated clashes on Brazilian soil in the 19th century.Restricting divergences in the literacy process to the methodological aspect of adopting these marches reiterates the technical bias decoupled from the social, historical, political and cultural context of the subjects involved.
\end{abstract}

Keywords: Literacy. Castilho. Jacotot.

\title{
Resumen
}

Al indicar la "instrucción fónica sistemática" como uno de sus principios orientadores, la Política Nacional de Alfabetización (2019) resuena una latente discusión metodológica imperial que atravesaba las querellas entre las marchas sintética y analítica en la enseñanza de la lengua materna. Este artículo presenta las matrices del método fónico creado por el portugués António Feliciano de Castilho (1855) y del método analítico de Enseñanza Universal creado por Joseph Jacotot (1834), que circularon y generaron enfrentamientos en suelo brasileño en el siglo XIX. Restringir las divergencias del proceso de alfabetización al aspecto metodológico de adopción de estas marchas reitera el sesgo tecnicista desacoplado del contexto social, histórico, político y cultural de los sujetos involucrados.

Palabras clave: Alfabetización. Castilho. Jacotot. 


\section{Introdução}

No contexto histórico brasileiro de indicação da "instrução fônica sistemática" como um dos princípios norteadores da Política Nacional de Alfabetização ${ }^{2}$ (2019), a república no século XXI faz ecoar uma latente discussão metodológica imperial. Nesse âmbito, presencia-se a permanência da redução da discussão epistemológica e política sobre a importância do ato de ler para as querelas das marchas sintética e analítica de alfabetização.

Tais matrizes do ensino de leitura adentraram no Brasil imperial: a sintética de António Feliciano de Castilho ${ }^{3}$ (1800-1875) e a analítica de Joseph Jacotot ${ }^{4}$ (1770-1840), apresentando disputas e demarcando a década de 1850 como palco de experimentações pedagógicas no campo da alfabetização no Império brasileiro.

Passado mais de um século, observam-se as permanências de discursos que reduzem a questão da alfabetização ${ }^{5}$ ao método e à técnica, tomando como centro da discussão o ponto de partida do ensino (letras, sílabas, sons, palavras ou textos).

$\mathrm{Na}$ medida em que apresenta uma diretriz pretensamente científica, fundamentada na concepção de alfabetização sob o prisma de uma marcha sintética, "que deve ser ensinada de forma explícita e sistemática, numa ordem que deriva do mais simples para o mais complexo" (BRASIL, 2019, p. 18), a atual Política Nacional de Alfabetização (2019) reduz o desafio da práxis social que engloba o processo de alfabetização a questões como sonoridade e/ou ponto de partida de uma marcha metodológica.

A Política Nacional de Alfabetização (PNA), instituída por decreto presidencial de 11/4/2019 (BRASIL, 2019a), conforme observam inúmeros autores (MORTATTI, 2019; CARDOSO; GUIDA; SEPÚLVEDA; PAULET, 20019; FRADE, 2019), integra um projeto político-ideológico neoliberal e ultraconservador do atual governo federal, estando estrategicamente articulada às demais medidas de destruição dos avanços democráticos conquistados pela população brasileira nas últimas décadas.

Ao indicar a matriz sintética e fônica como diretriz para o ensino da leitura e da escrita, a Política Nacional de Alfabetização (2019) tenta abrandar sua leitura impositiva do processo de alfabetização, declarando que "basear a alfabetização em evidências de pesquisas não é impor um método, mas propor que programas, orientações curriculares e práticas de alfabetização sempre tenham em conta os achados mais robustos das pesquisas científicas" (BRASIL, 2019, p. 20). É claro que se poderia dizer, com Isabel Cristina Alves da Silva Frade (1919, p.15), que "embora a proposta do PNA busque construir uma noção de evidência baseada em pesquisas experimentais, há um conjunto de evidências empíricas, oriundas de outras pesquisas, que permitem fazer outras indagações".

\footnotetext{
${ }^{2}$ Segundo Frade e Monteiro (2019), a publicação do Decreto no ${ }^{-9.765}$, de 11 de abril de 2019, que instituiu a Política Nacional de Alfabetização (PNA), e a publicação do caderno "Política Nacional de Alfabetização", divulgado pelo Ministério da Educação, no dia 15 de agosto de 2019, "evidenciam os pressupostos que orientam os rumos e as estratégias que estão sendo pensadas para a Política Nacional de Educação", sendo tais escolhas baseadas em "dois paradigmas de pesquisa: o da Ciência Cognitiva e o da Neurociências" (FRADE; MONTEIRO, 2019, p. 10).

3 António Feliciano de Castilho (1800-1875) foi um educador português, poeta, bacharel em Direito pela Universidade de Coimbra e sócio da Academia Real das Ciências de Lisboa, e criou o Metodo Castilho para o ensino rapido e aprasivel do ler impresso, manuscrito, e numeração e do escrever (ALBUQUERQUE, 2019, p. 23).

${ }^{4}$ Jacotot (1770-1840) foi um educador francês, criador do Ensino Universal. Ele entrou com 9 anos no Collége des Godrans, onde passou 33 anos como aluno e depois como professor (RAISKY, 2012, p. 18). Em Dijon, ensinou "Análise, Ideologia e Línguas Antigas, Matemáticas Puras e Transcendentes e Direito" (RANCIÈRE, 2015, p. 17).

${ }^{5}$ No século XIX não era comum a utilização da palavra alfabetização para se referir ao ensino da leitura e da escrita. Contudo, por pretendermos estabelecer um paralelo entre o passado e o futuro, valemo-nos do termo, entendendo, portanto, que, por seu uso corrente em língua portuguesa hoje, ele não constitui propriamente um anacronismo.
} 
Mesmo mencionando a possibilidade de não restringir a questão da alfabetização a um método, a referência a autores como Snow (1998), na forma como foram inseridos no documento, reafirma que "todas as divergências sobre o ensino de leitura começam com a alegação de que é preciso fazer uma ou outra dessas coisas no começo da alfabetização" (SNOW, 1998, apud BRASIL, 2019, p. 30).

Restringir "todas" as divergências sobre o ensino de leitura ao aspecto metodológico, no tocante à adoção das marchas sintética, analítica ou mista, reitera um viés tecnicista na abordagem do processo de alfabetização, retirando-o de seu contexto social, histórico, político e cultural dos sujeitos envolvidos; falácia essa criticada pelo próprio documento:

O analfabetismo nos dias atuais está claramente associado a condições adversas de vida, geralmente relacionadas à pobreza e geradoras de diferentes formas de vulnerabilidade social, que se expressam em moradia e saneamento precários, meios de subsistência quase inexistentes e falta de oportunidade de usufruir de todos os direitos e deveres da cidadania (MALUF, apud BRASIL, 2019, p. 19).

No entanto, o que se vê na construção do próprio documento é a instauração de um processo que veio de cima para baixo, por decreto presidencial, sem qualquer debate com a comunidade acadêmica e com o magistério (MORTATTI, 2019, p. 27). Na contramão dessa proposta política que faz da matriz fonética do sistema alfabético uma camisa de força para introduzir famílias silábicas em sua marcha gradativa, restringindo com isso a possibilidade de experimentações e de modos de ensinar alternativos, por sobrepor a base sobre todos os demais fatores intervenientes no ato de alfabetizar, o presente artigo tem por propósito estabelecer um diálogo histórico com a realidade atual, evidenciando, para o caso brasileiro, um momento em que provavelmente a discussão sobre a maneira fônica de se alfabetizar entrou no debate, quando se introduziu a relevância do som e do ouvido (SCHAFER, 1991) para efetivar a alfabetização das crianças.

Ao revisitar um embate imperial acerca da importância da sonoridade no ensino da língua materna ou do ensino da leitura e da escrita, este artigo pretendeu, portanto, apresentar os desafios da formação de um sujeito considerado em sua capacidade construtora e criativa e que interage com o contexto de produção do texto o qual se debruça, transformando-o e sendo por ele transformado sob o prisma de uma dialética no processo de alfabetização.

Trazendo luz a questões metodológicas atuais no que toca à introdução do som e da música no ensino da língua materna, foi abordada a definição de leitura auricular apresentada no Método de Castilho, o qual, em 1850, constituía um importante antecedente, talvez mesmo a matriz do método fônico ${ }^{6}$ em Portugal — tendo ressonância no Império brasileiro. Poeta cego, Castilho viveu o que teorizou Schafer (1991) a respeito da idiossincrasia do ouvido que, ao contrário de outros órgãos dos sentidos, não pode ser fechado, estando sempre exposto e vulnerável, captando os sons do horizonte acústicos em todas as direções.

Ao desenvolver a leitura auricular, Castilho rompeu com o método da antiga soletração em que se partia do conhecimento de cada letra do alfabeto para a composição das sílabas como início do processo de alfabetização, passando a respeitar como ponto de

\footnotetext{
${ }^{6} \mathrm{~A}$ definição do método de António Castilho em uma marcha sintética e fonética foi trabalhada na tese de Albuquerque (2019). Apesar de Castilho não possuir elementos teóricos bem definidos naquele momento para definir as marchas analítica e sintética e sequer intitular seu método como fônico, observa-se um processo histórico de construção de ruptura entre essas marchas e ainda de diferenciação nos métodos de marcha sintética, uma vez que sua ruptura com a antiga soletração e silabação consistia em "evocar a sonoridade das palavras como pontapé inicial do ensino da leitura” (ALBUQUERQUE, 2019, p. 94).
} 
partida do mesmo percurso a sonoridade da palavra falada, tal como fez o que posteriormente será denominado método fônico.

Se na pauta das discussões no atual cenário político estão as questões da alfabetização centradas entre marchas sintética ou analítica, é necessário problematizar acerca da importância do ato de ler para a emancipação do sujeito; e, para tanto, retoma-se com Jacotot excelência do Ensino Universal para a formação de leitores autônomos e criativos. Os embates entre os defensores de Castilho e Jacotot em solo imperial brasileiro no século XIX resultaram de diferentes concepções filosóficas referentes ao processo de alfabetização. Jacotot, com seu princípio do ensino do todo relacionável, encontrou resistências em uma espécie de redes de saberes filosóficos que fundamentaram os métodos para o ensino de leitura nos séculos XIX e XX. O Ensino Universal proposto por Jacotot evocava a liberdade criativa, partindo do todo no ensino da língua materna a partir, inclusive, do ensino de música. Jacotot tinha por base o princípio da totalidade de um texto como início do processo de alfabetização, rumo àquilo que viria a ser caracterizado pela posteridade como método analítico ou global. Jacotot foi considerado por vários pedagogos como o criador do método analítico para o ensino da leitura através de seu Ensino Universal apresentado na obra Língua materna, publicada em 1822.

Verifica-se que esse embate imperial de alguma maneira repercute nas práticas das atuais escolas republicanas, quando se apresenta novamente a ambivalência no ensino da leitura e escrita à luz do anúncio de um método fônico que, entretanto, se vale de argumentos historicamente vinculados à defesa do ensino analítico.

$\mathrm{Na}$ contramão de uma centralidade no sujeito ou ainda no alicerce do processo de alfabetização (texto, palavra, sílaba, fonema etc.) esvaído de sua práxis social, cabe lembrar a necessidade sempre presente no processo de alfabetização de uma "leitura do mundo" (FREIRE, 1989, p. 12) e do todo relacionável à leitura da palavra; desafio esse que extrapola as questões técnicas e metodológicas de preocupação com as marchas sintéticas e analíticas e que leva a que se assuma os educandos em sua condição de sujeitos que devem ser aproximado do direito a bens culturais e materiais humanamente construídos.

\section{A leitura auricular do Método Castilho: marcha sintética e música na alfabetização}

António Feliciano de Castilho nasceu em $26^{7}$ de janeiro de 1800, na rua da Torre de S. Roque, em Lisboa, hoje rua de S. Pedro de Alcântara, e era o segundo filho e primeiro varão de Domitília Máxima da Silva e do médico José Feliciano de Castilho que trabalhou no serviço da Corte como inspetor de hospitais e lente de prima da Universidade de Coimbra.

Foi um poeta português que se lançou na instrução pública e que, a partir da sua experiência com o ensino dos insulanos da ilha de São Miguel, teceu severas críticas aos modelos de escolas de sua época, atraindo para si vários opositores. Para António Castilho, leitura e escrita faziam parte de uma mesma moeda, sendo imprescindível apresentar as letras a partir de elementos já conhecidos da palavra falada.

Cada ideia é imagem de um objeto, cada palavra falada representação de uma ideia; cada palavra escrita representação de uma palavra falada; cada palavra lida tradução fônica de uma palavra escrita. O ler é portanto dependente da escrita, como a escrita dependente do falar. Para bem se ensinar devia começar-se por estudar e reconhecer a palavra falada (CASTILHO, 1853, p. 26).

\footnotetext{
${ }^{7}$ Apesar de haver controversas entre as datas localizadas acerca do nascimento de António Feliciano de Castilho, adotamos a apresentada nas Memórias de Castilho, obra escrita por seu filho Júlio de Castilho (CASTILHO, 1926, livro I, p. 5).
} 
António Castilho considerava ser o criador de um método que atentava para a análise minuciosa da palavra falada, pois, após a leitura auricular, era feita a decomposição desta em sílabas para distinção de seus elementos. Partir da palavra falada para chegar às letras isoladas, essa é a máxima do método português; apresentar a palavra falada antes da escrita; "a palavra falada não se pode fazer palavra escrita elementarmente, senão dividindo-se elementarmente; dividiu-se sem custo em sílabas; subdividiu-se das sílabas ainda em elementos" (CASTILHO, 1999b, p. 114).

Com fundamento na definição do método de leitura de Braslavsky (1971), pode-se situar António Castilho na defesa do método fonético, justamente por partir da palavra falada para a decomposição desta em elementos e, dessa forma, reivindicar a primazia da linguagem falada da aprendizagem da leitura, indo do que se "ouve e fala" para chegar ao que se "escreve e vê".

Quando analisarmos as correntes que atualmente tratam de interpretar esse processo, veremos que todas coincidem em destacar o papel que desempenha a linguagem falada como antecendente da aprendizagem da leitura, e que, para chegar a ela, parte-se da linguagem que se ouve e que se fala, chegando-se depois ao que se escreve e se vê, segundo os símbolos convencionais representados numa superfície (BRASLAVSKY, 1971, p. 56).

Na proposta de António Castilho, ao processo de decomposição e análise das palavras, estava atrelado o processo de composição e síntese. Tão logo os discípulos conseguiam seguir a marcha da decomposição, o mestre elencava as palavras isoladas para que estes juntassem em sílabas e palavras; "decomponham palavras, componham-nas; tem andado no caminho que leva pela escrita à leitura, entrem no que leva pela leitura, são por este método inseparáveis" (CASTILHO, 1853, p. 23).

A leitura auricular consistia na decomposição e síntese do objeto de leitura: a palavra falada. Seguem dois exemplos da decomposição da palavra trabalhada inicialmente em um contexto globalizante.
MESTRE $=F, e, r ; m, e m ; t, u$ ?
CÔRO DE DISCIPULOS = Fer; men; tu: Fermento .
$\operatorname{MESTRE}=\mathrm{Q}$, â; r, â; v, é; 1 , â?
CÔRO DE DISCIPULOS = Ca; ra; ve; la: Caravela .
É isto o que nas nossas escolas se chama leitura auricular.

Boto (2012, p. 57) define a leitura auricular como uma "biforme repetição do mesmo processo", que inicia com a decomposição do objeto da leitura - a palavra —, para que o aluno reconhecesse seus elementos sonoros correspondentes aos valores da escuta das letras.

Compreendendo que a habilidade da leitura deriva da competência da fala, o método de Castilho, que se pretende explicitamente simples, eficaz e rápido, combina, analisa e disseca sons da palavra falada, decompondo-a em seus elementos fônicos e recompondo-a na sua totalidade de significado. É para tanto que Castilho sugere práticas entrelaçadas de decomposição das palavras em letras, atribuindo a estas a sonoridade que lhes seria original, para reconstituir, no final, a lógica da palavra inteira (BOTO, 2012, p. 56). 
Tal método baseava-se no ritmo a ser acompanhado pelos discípulos com uma palmada ou pancada de vara a cada palavra, sílaba ou letra proferida, sendo indispensável o uso do compassador - "máquina que ideei para marcar aos olhos e aos ouvidos os tempos com qualquer grau de velocidade desejável, a cadência rítmica com muito mais facilidade se adquirirá e com muita mais perfeição" (CASTILHO, 1853, p. 16). A marcha também estava presente para marcar a decomposição da palavra em sílabas e desta em letras.

Este exercício, em que tem de se harmonizar três coisas, o movimento dos pés, o das mãos, e a voz, é forçosamente irregular e quase tumultuário no seu princípio, mas como é parte importantíssima para o ritmo, convém aplicar-lhe todo o cuidado até se obter a marcha silábica perfeita; também para aqui pode ser de grande auxílio o compassador (CASTILHO, 1853, p. 20).

A marcha fonética proposta por António Castilho consistia em um exercício de decomposição da palavra pela leitura auricular. Depois desse exercício, prosseguia-se à leitura ocular, em que eram apresentados quadros de formas e sons de letras. Assim que os discípulos estivessem adiantados na leitura de palavras soltas, antes de passarem da segunda classe para a terceira, seria introduzido o estudo da escrita que, mutuamente, se auxiliariam.

Ao relegar o ensino da escrita a um segundo plano, após a aprendizagem da leitura, constata-se que algumas renovações propagandeadas por Castilho não eram efetivadas na materialização de seu método.

Ainda que se pretendesse renovador, o Método Castilho supunha o aprendizado da escrita posteriormente à aquisição da leitura, tal como ocorria cotidianamente no interino das escolas portuguesas. Para Castilho, haveria inclusive uma anterioridade lógica da leitura sobre a escrita (BOTO, 2012, p. 55).

De modo prático, o professor seguido pelo discípulo dizia uma palavra, depois repetia e a dividia compassadamente em sílabas, marcando cada sílaba com um passo e com uma pancada sonora da mão direita na mão esquerda. Após essa decomposição inicial das palavras em sílabas, passaria a uma decomposição em letras. O exercício que até então estava limitado aos ouvidos e boca, passava para um terceiro estágio, a leitura ocular, na qual as letras móveis, fixadas na grade, passavam a compor palavras, a partir do agrupamento das letras móveis.

Para escrever, restava-lhe saber fazer letras de mão. Para isso, o professor utilizava cartões pretos com letra pintada com tinta branca, ordenados em ordem crescente de dificuldade, e os discípulos com giz, lápis branco ou lápis de pedra copiavam na ardósia ou tábua preta. Segue-se a ordem do processo.

O processo para a escrita de cada uma destas palavras deve ser invariavelmente o seguinte: apenas o discípulo a ouve, repete-a desmembrada em sílabas com uma palmada da mão direita na esquerda; depois pronuncia a primeira sílaba à moda de bêbado, isto é, estirando a voz por todos os elementos de que ela consta; finalmente: esses mesmos elementos ou letras que proferiu, escreve-os seguidamente, faz o mesmo com a segunda sílaba, o mesmo com a terceira, se a há, e assim até ao cabo, de maneira que, por mais comprida que seja uma palavra, a atenção nunca se acha carregada de mais de uma só sílaba (CASTILHO, 1975, p. 154). 
Foram várias as querelas pedagógicas envolvendo os defensores de Castilho diante da matriz do francês Joseph Jacotot no Brasil imperial. As atividades envolvendo a relação entre professor e discípulos, o material escolar, os tempos e espaços estão bem representados na apresentação do método de Castilho. Talvez por isso o autor tenha sido tão crítico ao Ensino Universal de Jacotot que, para ele, estava recheado de aforismos e carecedor de explicações pontuais que envolviam o cotidiano escolar e a materialização do método analítico proposto.

Dessa forma, verifica-se que Jacotot com seu princípio do ensino do todo relacionável e proponente de uma teoria de emancipação na instrução por diversas vias, como no ensino da língua materna e da música, encontrou resistências em uma espécie de redes de saberes filosóficos que fundamentaram os métodos para o ensino de leitura nos séculos XIX e XX.

\section{Ensino Universal em Jacotot: a liberdade criativa e a evocação do todo no ensino da língua materna}

Jean Joseph Jacotot (1770-1840) nasceu em Dijon, França, e foi considerado um revolucionário questionador dos resultados da Revolução Francesa e das instituições de sua época por julgar que esses movimentos não trouxeram meios para atingir a liberdade e a emancipação do homem, inclusive no campo intelectual.

Exilado de seu país, com o cessar da Revolução de 1830, o mestre regressou à França na tentativa de propagar seu método de ensino, buscando a "Emancipação Intelectual" dos envolvidos na instrução. Esse contexto é apontado por Rancière (2015) como a conciliação da ordem e progresso, a partir da instituição pedagógica que viu triunfar o "velho" sob o silenciamento das febres igualitárias e das desordens revolucionárias e de vozes como de Jacotot. O princípio pedagógico do Ensino Universal criado por Jacotot referia-se a aprender algo e relacionar a esse saber todo o resto, em virtude do princípio da igualdade das inteligências.

Se você cair na mão de um aluno da escola de direito de Paris, e se este aluno da escola de direito de Paris pede para você dar o nosso método, aplicado ao estudo da lei, comece com estes termos: Jovem! É necessário aprender algo e relacionar todo o resto, deste princípio: todos os homens têm uma inteligência igual (JACOTOT, 1852, p. 8).

Jacotot partia da totalidade de um texto como princípio do processo de alfabetização, sendo percussor de método analítico ou global de ensino da leitura e da escrita. Segundo Aguayo (1959, p. 182), Jacotot teria sido o criador do método analítico para o ensino da leitura através de seu Ensino Universal apresentado na obra Língua materna (1834).

O contato do aluno com o todo do livro, da música, da poesia, dentre outros, era o começo do percurso de ensino da leitura, na contramão de uma marcha sintética como a de Castilho, que reservava esse reconhecimento do todo apenas aos alunos que atravessassem as agruras de uma sequência silábica lógica em sua sonorização e representação do som em sinais gráficos.

A defesa de Jacotot pela emancipação intelectual pela via do ensino da língua da materna e da música com base no ensino do todo estava em consonância com sua Filosofia Panecástica. A definição do termo Panecástica advém do princípio da igualdade dos seres falantes, fundamentado na máxima expressa em seu Ensino Universal que "tudo está em tudo".

Rancière (2015) explicita a composição do termo Panecástica a partir da junção de duas palavras gregas, pan = todo e ekastos = cada um, "buscando o todo da inteligência humana em cada manifestação individual” (RANCIÈRE, 2015, p. 64). 
No primeiro Congresso Brasileiro de Proteção à Infância, realizado de 27 de agosto a 5 de setembro de 1922, no Rio de Janeiro, Clemente Quaglio ${ }^{8}$ definiu o Ensino Universal de Jacotot em trabalho intitulado "Qual o método de ensino da leitura que mais de perto acompanha a evolução mental da criança?". Com base nessa discussão de Quaglio, em um evento no ano de 1942, pode-se observar a longevidade da discussão sobre métodos de alfabetização.

Segundo Quaglio (1925), o Método de Jacotot foi uma tentativa de substituição do método silábico pelo método proporcional (Analítico ou Método de Sentenciação). Contextualizando a máxima Panecástica de Jacotot segundo a qual "tudo está em tudo", Quaglio demonstrou o princípio do ensino por meio da leitura de Telêmaco, em que Jacotot propôs que o "professor fizesse aprender de cor uma página de um livro de leitura, uma regra de aritmética, um trecho de música, e que a estas lições especiais se relacionassem todas às sucessivas" (QUAGLIO, 1925, p. 494).

Com a máxima de Jacotot de que "tudo está em tudo", o aluno que ainda desconhecia o alfabeto era colocado inicialmente em contato com um livro, uma página decorada e uma frase; após essa sentença, o aprendiz encontraria alguns sinais semelhantes e iguais e, depois das comparações, relacionaria ao todo.

Para o princípio de alfabetização do método analítico de Jacotot, a sentença era utilizada como estratégia ao iniciar pela comparação de palavras e pelo isolamento de elementos nelas reconhecidos para a leitura e escrita de novas palavras.

Ele punha diante da vista esta frase: "No começo, Deus criou o Céu e a Terra; mas a Terra era sem forma e vazia”. Depois de haver lido a frase ao seu aluno, convidava-o a considerá-la atentamente e a refletir. $\mathrm{O}$ aprendiz achará bem depressa alguns sinais semelhantes e iguais, como por exemplo os a, i, u etc. (QUAGLIO, 1925, p. 495).

Dessa forma, partindo do desconhecido do todo do livro, a criança identificaria as diferentes palavras e expressões, todos os sinais apresentados estariam sujeitos à discussão e à contestação. O princípio Universal estabeleceu-se ao mostrar uma escrita global para a criança e, em momento posterior, apresentar as estruturas reduzidas em sílabas ou letras à luz de relações de comparações, rompendo com o encadeamento gradativo de aprender primeiramente as letras, sílabas, e depois as palavras.

Toda palavra, toda expressão, todo sinal de pensamento está sujeito a discussão e contestação. Aprenda as letras, depois as sílabas, depois as palavras; você será capaz de ler, sem usar o método de ensino universal, mas se, depois de ter mostrado as cartas a uma criança, ele é informado de relatos, palavras que ele ainda não conhece e as sílabas que aprendeu, teremos feito Ensino Universal (JACOTOT, 1834, p. 12).

O princípio de emancipação defendido por Jacotot, na contramão de um mestre que dirigia todos os passos, levando o aluno ao embrutecimento, foi trazido por Quaglio, ao escrever que "o mestre não deve explicar coisa alguma; o aluno deve descobrir tudo por si

\footnotetext{
8 A partir do projeto "Clemente Quaglio (1872-1948): cânon da ciência pedológica - estudo históricocrítico", Monarcha demarca aspectos da produção científica desse pedagogista. De acordo com Monarcha (2011), Clemente Quaglio (1872-1948) nasceu na província de Rovigo, Itália, e faleceu em São Paulo; ao chegar ao Brasil, em 1888, fixou-se na cidade de Serra Negra, SP; em 1891, aderiu à "grande naturalização" oferecida pelo Governo Provisório da República, liderado por Deodoro da Fonseca, e após assumir uma escola isolada em Serra Negra (1895), foi nomeado adjunto no Grupo Escolar "Luiz Leite” e, por fim, ingressou no Grupo Escolar "Rangel Pestana", em Amparo, São Paulo. Em sua trajetória, projetou-se "nas fileiras do magistério nacional como autoridade científica” (MONARCHA, 2011, p. 1).
} 
mesmo" (QUAGLIO, 1925, p. 495). O mestre Jacotot, colocava-se na posição de "mestre ignorante" como forma de romper com esse embrutecimento de seus alunos, garantindo que seus pequenos "tocam, compõem e improvisam" (JACOTOT, 1824, p.24).

$\mathrm{Na}$ obra sobre o ensino de música a partir do princípio do Ensino Universal, Jacotot encontrava-se "disposto a ajudar com todo o poder no modelo que alguns deles podem ter, envolver seus cidadãos em benefício de informação e universal" (JACOTOT, 1824, p. 293).

A sinalização desse envolvimento do "todo" no processo de alfabetização está acoplado a uma perspectiva sensorial do processo de alfabetização; e, na lógica de Hamilton (2002), representa diálogo entre o presente e o passado. O fato é que se observa nesse embate do Império brasileiro, muitas das questões contemporâneas no debate pedagógico nacional e que acabam por se refletir na Política Nacional de Alfabetização (2019). Cabe sobretudo questionar a aparente supremacia de métodos e técnicas sobre todos os demais fatores envolvidos no desafio do aprendizado da leitura e da escrita. Mortatti comenta a pretensa novidade do método fônico com as seguintes palavras:

O método fônico/instrução fônica é a solução nova e científica para os problemas da alfabetização no Brasil, porque é o único fundamentado em evidências científicas: essa falsa premissa e os argumentos decorrentes são invalidados por resultados de pesquisas científicas a comprovarem que esse método não é novo na história da alfabetização no Brasil, nem solução para os problemas da alfabetização, e sua pretendida eficácia universal foi e vem sendo questionada, no Brasil e no exterior, com base em resultado de outras pesquisas científicas (MORTATTI, 2019, p. 28).

\section{Desafio da leitura do mundo à leitura da palavra: problemáticas da PNA}

Corroborando a teoria de Magda Soares (2017), observa-se que a "velha" discussão sobre os métodos de ensino não foi ainda vencida. Historicamente, nota-se no debate pedagógico dos dias de hoje um silenciamento e um reducionismo da fala governamental acerca do trajeto da discussão acadêmica sobre os métodos de alfabetização, relegando-a ao campo das querelas das marchas pedagógicas e mascarando o todo social, o que pode levar a uma ortodoxia da escola conduzida por um viés impositivo e autoritário de um método único. A partir da ótica de uma pergunta - Alfabetização: em busca de um método? -, a autora responde destemidamente sobre a necessidade de estarmos sempre em busca de um método, defendendo, no entanto, uma reflexão na conceituação de método, e um diálogo entre a procura do método e todos os demais fatores que envolvem o processo de alfabetizar.

Há uma tentativa histórica de reduzir essa discussão social e política dos métodos de alfabetização às estratégias metodológicas das marchas. Buscamos suprimir as disputas no campo da língua, projeto de nação, dentre outros. Em uma tentativa perversa de reduzir o caminho da aquisição da linguagem escrita a uma lógica metodológica, perde-se o que há, nesse trajeto, de projeto social, político e histórico.

Revisitar esse debate sobre a alfabetização apresentado na instrução imperial, em um momento de constituição da nação, língua e povo brasileiro corrobora a perspectiva de Magda Soares (2017), no tocante a voltar a discussão para além de querelas pedagógicas. Qualquer que fosse o método, estavam em jogo projetos de nação. A disputa pedagógica restrita ao caráter metodológico e centrado entre marchas e modos de ensino ocultava, e ainda oculta, os conflitos e lutas associados ao processo de constituição da nação brasileira.

Restringir as divergências do processo de alfabetização ao aspecto metodológico reitera um viés tecnicista do tema, desacoplando a marcha da alfabetização de seu contexto social, histórico, político e cultural. Isso é o que aparece na Política Nacional de 
Alfabetização, sob argumentos pretensamente calcados em evidências científicas. Ao questionar até "que ponto um paradigma científico pode alterar radicalmente os resultados da alfabetização?”, Frade (2019) afirma o que segue:

No ato pedagógico temos uma série de variáveis relativas, por exemplo, às expectativas sociais sobre para que se alfabetiza; ao contato que sujeitos e grupos têm com a cultura escrita; ao modo como os professores alfabetizadores mobilizam esses saberes ou os ampliam; aos procedimentos que vão se consolidando para ensinar a ler e escrever; à administração do tempo das atividades; à interpretação do contínuo das participações, das redes de relações e das interações que ocorrem no espaço da sala de aula; às formas de manter os alunos participando; aos modos de atenção dados às indagações de cada aluno; aos seus tempos de aprendizagem; aos materiais disponibilizados; entre outras variáveis (p.16).

Em Castilho, a aprendizagem do código escrito do sistema alfabético precisa de uma sonoridade, sendo observada em sua didática a busca de uma marcha alegre, ritmada e regulada sob a regência do mestre professor. Em Jacotot, uma capacidade criativa dá oportunidade ao sujeito de experimentar os sons sob a primazia da construção dos saberes. Tais propostas, que pareciam antagônicas em seu tempo, nos dias atuais necessitam ser redimensionadas para o reconhecimento de vozes, ritos e práticas que têm sido silenciadas em nosso contexto político e social.

Kohan (2019) define a proposta do francês Jacotot como uma emancipação intelectual e individual, sugerida no século XIX, baseada no princípio da igualdade das inteligências. Pensando com Lilian do Valle (2003), torna-se essencial, ao estudar trabalhos filosóficos como o de Jacotot, irmos para além da mera discussão metodológica (VALLE, 2003, p. 263). Na mesma perspectiva, Rancière (2015) observa a atualidade do discurso de Jacotot:

não se trata de uma questão de método, como em formas tradicionais de aprendizagem, trata-se de uma questão propriamente filosófica: saber se o ato mesmo de receber a palavra do mestre - a palavra do outro - é um testemunho da igualdade ou desigualdade. É também uma questão política, ou seja, saber se o sistema de ensino tem por pressuposto uma desigualdade a ser "reduzida", ou uma igualdade a ser verificada (p. 12).

Nas palavras de Raisky, no paradoxo de Jacotot, a pedagogia deveria estar a serviço da "emancipação intelectual do indivíduo (seja qual for o nome dado a esse objetivo), mas, ao mesmo tempo, deve prepará-lo para desempenhar um papel social, ocupar um lugar no mundo, na ordem econômica e política, porque será a condição de sua existência" (RAISKY, 2012, p. 117). Tais concepções extrapolam o reducionismo da alfabetização ao prisma sensorial, sendo central o questionamento:

Assim, por que há, na PNA, um discurso mais centrado em habilidades de instrução fônica, fluência e vocabulário, sem sua vinculação intensa com os textos? A impressão é que estas habilidades ainda aparecem na PNA, sem a correlação entre essas habilidades, numa espécie de cadeia evolutiva, como se a compreensão, por exemplo, não pudesse ser trabalhada antes da instrução fônica, como se o vocabulário não dependesse também do acesso aos textos (FRADE, 2019, p. 20). 
Como assinalam também Cardoso, Guida, Sepúlveda, Paulet (2019, p. 94), a Política Nacional de Alfabetização, "ao pautar a denominação de evidência científica a partir de metanálises produzidas em torno de uma única tradição acadêmica, descarta décadas de pesquisa feitas em diferentes lugares do mundo". Tratar-se-ia, segundo as autoras, de uma visão reducionista em todos os sentidos, inclusive no próprio sentido metodológico, que se propõe a ser o único valorizado, exatamente porque se parte do pressuposto de que "apenas a neurociência e a ciência cognitiva são fontes suficientes, desprezando outras perspectivas disciplinares" (CARDOSO; GUIDA; SEPÚLVEDA; PAULET, 2019, p. 94). Cabe, portanto, apenas concordar com o diagnóstico produzido pelas mesmas autoras:

Estamos sob a égide de um governo que tem operado em uma lógica binária, mecanismo que tenciona a oposição a fim de cristalizar uma nova verdade. E a PNA está ancorada nessa mesma lógica: nega o que se construiu até aqui para começar em novas bases; lança mão de um diagnóstico parcial que não considera os avanços alcançados; inaugura um novo vocabulário (literacia, numeracia e parentalidade) desconsiderando terminologias técnicas consolidadas; coloca em um mesmo pacote todos os pesquisadores, estudiosos e professores que trabalham a partir de outros paradigmas; e reduz o olhar do professor alfabetizador a apenas uma das dimensões que estão em jogo no que se refere ao ensino e à aprendizagem da leitura e da escrita (p. 96).

\section{Considerações finais}

António Feliciano de Castilho criou um método de ensino de leitura e da escrita com a presença de um mestre que regularia todas as fases do processo, tendo seu tempo e espaço demarcados como uma grande orquestra escola. A proposta teórica do ensino analítico apresentada por Jacotot entrou em rivalidade no Império brasileiro com os apropriadores da marcha sintética defendida por Castilho.

Pensar a educação a partir de uma perspectiva de longa duração permitiu-nos problematizar a forma como matrizes internacionais postas no campo da instrução pública no Império brasileiro perfez caminhos de continuidades e rupturas com a nossa atual República. Dentre idas e vindas, levantar questionamentos a respeito da questão social e política que envolve o ato de ler extrapola a mera questão metodológica da adoção de um método fônico ou do método analítico.

O desconhecimento de aspectos multifacetados absolutamente desconsiderados no documento da Política Nacional de Alfabetização restringe a questão da alfabetização a estudos de base cognitivas e metodológicas; e silencia a consciência social, histórica e política do processo, como se fôssemos voltar ao Império brasileiro para retomar uma perspectiva do debate que estava lá, naquele específico momento histórico. Trata-se, portanto, de um voltar para trás, de um regresso para meados do século XIX.

Já que é retornar, poderíamos, pelo menos, resgatar a atualidade de Jacotot: o desafio da inversão da lógica explicadora de um mestre que é o único detentor do conhecimento e dos passos do processo de alfabetização racionalmente marchados, diante de um processo que possibilita ao aluno uma emancipação na composição da sinfonia do processo de associação dos sons que o cercam - sons que extrapolam o livro didático e a sala de aula.

Pretendemos, portanto, neste artigo, confrontar o debate pedagógico do Império brasileiro sobre as políticas de ensino da leitura e da escrita com a atual Política Nacional de Alfabetização (2019), em vigência no Brasil de nossos dias, posto que, em ambos os casos, há 
um reducionismo da problemática da alfabetização, tomada exclusivamente pelo debate entre marchas, sintéticas ou analíticas, ora centradas no texto, ora no sujeito, e que silenciam os sons da capacidade transformadora do sujeito em relação a sua realidade social. A alfabetização é uma conquista que deve estar ao alcance de todos como um direito público subjetivo; mas que, enquanto tal, está muito para além da querela dos métodos de ensino.

\section{Referências}

AGUAYO, A.M. Didática da Escola Nova. PENNA, J. B. Damasco; D’AVILA, Antônio (trad. e notas). São Paulo: Cia. Editora Nacional, 1959. (Atualidades Pedagógicas, 15.)

ALBUQUERQUE, Suzana Lopes de. Métodos de ensino de leitura no Império brasileiro: António Feliciano de Castilho e Joseph Jacotot. 2019. 240f. Tese (Doutorado em Educação) Faculdade de Educação. Universidade de São Paulo, USP, 2019.

BOTO, Carlota. A escola primária como rito de passagem: ler, escrever, contar e se comportar. Imprensa da Universidade de Coimbra, 2012.

BOTO, Carlota; ALBUQUERQUE, Suzana Lopes de. Entre idas e vindas: vicissitudes do método Castilho no Brasil do século XIX. História da educação (on-line). Porto Alegre, v.22 n.56, set.-dez., p. 16-37, 2018. https://doi.org/10.1590/2236-3459/70697

BRASIL. Ministério da Educação. PNA. Política Nacional de Alfabetização. Secretaria da Alfabetização. Brasília: MEC, Sealf, 2019.

BRASLAVSKY, Berta P. de. Problemas e métodos no ensino da leitura. São Paulo: Melhoramentos e Editora da USP, 1971. MINICUCCI, Agostinho (trad.). Prof. Lourenço Filho (Prefácio).

CARDOSO, Beatriz; GUIDA, Andrea; SEPÚlVEDA, Angélica; PAULET, Nicole. Contribuições para o debate sobre alfabetização a propósito do lançamento da PNA. Revista Brasileira de Alfabetização. Edição Especial: Dossiê Política Nacional de Alfabetização em Foco: olhares de professores e pesquisadores. n.10. 2019. p. 94-96.

CASTILHO, António Feliciano. Correspondência pedagógica. CASTELO-BRANCO, Fernando (seleção, introdução e notas). Instituto Gulbenkian de Ciência. Centro de Investigação Pedagógica. Lisboa, 1975.

CASTILHO, António Feliciano. Método Castilho para o ensino rapido e aprasivel do ler impresso, manuscrito, e numeração e do escrever, 1853. Disponível em: $<$ http://sigarra.up.pt/up/web base.gera pagina?p pagina=1001565>. Acesso em: 20 dez._2012.

CASTILHO, António Feliciano. Resposta aos novíssimos impugnadores do método português. Lisboa: Empreza da História de Portugal, v.2, 1909 b.

CASTILHO, Julio de. Memórias de Castilho. Coimbra: Imprensa da Universidade, Livro I, Tomo I. 2. ed. 1926. 
FRADE, Isabel Cristina Alves da Silva. A escrita na Política Nacional de Alfabetização. Revista Brasileira de Alfabetização. Edição Especial: Dossiê Política Nacional de Alfabetização em Foco: olhares de professores e pesquisadores. Belo Horizonte, v.1, n.10. jul.-dez. 2019. p. 125-128.

FRADE, Isabel Cristina Alves da Silva. Um paradigma científico e evidências a ele relacionadas resolveriam os problemas da alfabetização brasileira? Revista Brasileira de Alfabetização. Edição Especial: Dossiê Política Nacional de Alfabetização em Foco: olhares de professores e pesquisadores. Belo Horizonte, v.1, n.10. jul.-dez. 2019. p. 15-25.

FRADE, Isabel Cristina Alves da Silva; MONTEIRO, Sara Mourão. Política nacional em foco: olhares de pesquisadores e professores. Revista Brasileira de Alfabetização. Edição Especial: Dossiê Política Nacional de Alfabetização em Foco: olhares de professores e pesquisadores. Belo Horizonte, v.1, n.10. jul.-dez. 2019. p. 10-13.

FREIRE, Paulo. A importância do ato de ler: em três artigos que se completam. São Paulo: Autores Associados, Cortez, 1989.

HAMILTON, David. O revivescimento da aprendizagem? Educação \& Sociedade, Campinas, v.23, n.78, p. 1-9, abr. 2002. https://doi.org/10.1590/S0101-73302002000200011

JACOTOT, Joseph. Enseignement Universel. Langue Maternelle. Paris: Chez Mansut fils, Cinquième Édition, 1834.

JACOTOT, Joseph. Enseignement Universel. Musique. Louvain, Chez F. Michel, Imp.-Lib., 1824.

KOHAN, Walter. Paulo Freire, mais do que nunca: uma biografia filosófica. Belo Horizonte: Vestígio, 2019.

MORTATTI, Maria do Rosário Longo. A Política Nacional de Alfabetização (Brasil, 2019): uma "guinada" (ideo) metodológica para trás e pela direita. Revista Brasileira de Alfabetização. Edição Especial: Dossiê Política Nacional de Alfabetização em Foco: olhares de professores e pesquisadores. Belo Horizonte, v.1, n.10. jul.-dez. 2019. p. 26-31.

QUAGLIO, Clemente. Qual o methodo de ensino da leitura que mais de perto acompanha a evolução, mental da creança? In: Primeiro Congresso Brasileiro de Protecção à Infancia. Rio de Janeiro: Empr. Graphica Editora, 1925.

RAISKY, Claude. Joseph Jacotot: Le pédagogue paradoxal. Dijon, Editions Raison et Passions, 2012.

RANCIÈRE, Jacques. O mestre ignorante: cinco lições sobre a emancipação intelectual. Tradução de Lílian do Valle. Belo Horizonte: Autêntica Editora, 2015, 3. ed.

SCHAFER, R. Murray. O ouvido pensante. FONTERRADA, Marisa Trench de O.; SILVA, Magda R. Gomes; PASCOAL, Maria Lúcia (trad.). São Paulo: Fundação Editora da Unesp, 1991.

SOARES, Magda. Alfabetização e letramento. São Paulo: Contexto, 2017.

VALLE, Lilian do. Pedra de tropeço: a igualdade como ponto de partida. Educação e Sociedade. Campinas, v.24, n.82, p. 259-266, abr,, 2003. https://doi.org/10.1590/S0101-73302003000100016 